\title{
Analysis of Parliamentary Election Results and Socio-Economic Situation using Self-Organizing Map
}

\author{
Pyry Niemelä and Timo Honkela \\ Helsinki University of Technology, Centre of Adaptive Informatics \\ P.O. Box 5400, 02015 TKK, Finland \\ timo.honkela@tkk.fi
}

\begin{abstract}
The complex phenomena of political science are typically studied using qualitative approach, potentially supported by hypothesisdriven statistical analysis of some numerical data. In this article, we present a complementary method based on data mining and specifically on the use of the self-organizing map. The idea in data mining is to explore the given data without predetermined hypotheses. As a case study, we explore the relationship between parliamentary election results and socio-economic situation in Finland between 1954 and 2003.
\end{abstract}

\section{Introduction}

In this article, we examine the possibility of exploring the relationship between the results of parliamentary elections over an extended period time and a number of political and societal variables that might influence these results. The data consists of (1) the results of the parliamentary elections between 1954 and 2003, (2) data indicating the parties in the government by the time of and before each election, and (3) a number of socio-economic variables such as unemployment rate. We are interested in finding relevant relationships between these variables (for related research within political science, see e.g., $[6,16,18]$ ). Rather than focusing on a set of specific hypotheses, we wish to explore if potentially useful relationships can be found by exploring a larger number of variables concurrently. Section 2 introduces the method, related research and the data collection. Some interesting and useful connections were found and they are reported in Section 3 . We are aware that some of the conclusions are preliminary and would require additional data or more detailed qualitative analyses. On the other hand, it also seems that the SOM provides additional insight that would be difficult to gain e.g. by plain inspection of the original data, by calculating correlations between the variables, or by fitting some linear model over the data. There are some alternative methods such as multidimensional scaling that could be considered but the SOM is a good choice especially when the trustworthiness is considered $[13,20]$. 


\section{Data and method}

The aim is to study the effect of socio-economic conditions on parties' approval ratings in Finnish parliamentary elections from the year 1954 to the year 2003. During chosen period there were no wars or other highly exceptional circumstances in Finland. In addition, it is easy to obtain reliable and comparable societal data from this period.

\section{$2.1 \quad$ Data}

The data consists of three parts. There are eleven variables of the elections, twelve variables of national economic conditions and ten variables of government responsibilities. The election data variables are the proportion of votes cast for the nine most important parties and the group of other parties and the turnouts in Finnish Parliamentary elections. The abbreviations, the English and Finnish names, and the former names of the parties are listed here:

- KESK: Centre Party of Finland, Suomen keskusta, until 1962 the Agrarian Union, in 1983 including Liberal Party.

- SDP: Social Democratic Party of Finland, Suomen sosiaalidemokraattinen puolue.

- KOK: National Coalition Party, Kansallinen kokoomus.

- LEFT: Left Alliance, Vasemmistoliitto, until 1987 the Democratic League of the People of Finland, in 1987 including Democratic Alternative.

- GREENS: Green League, Vihreä Liitto, in 1987 not as a party of its own.

- KD: Christian Democrats in Finland, Suomen kristillisdemokraatit, until 1999 Christian League of Finland.

- RKP: Swedish People's Party, Ruotsalainen kansanpuolue.

- PS: True Finns, Perussuomalaiset, in 1962 and 1966 the Small Holders Party of Finland and until 1995 the Finnish Rural Party.

- LIB: Liberals, Liberaalit, until 1966 the Finnish People's Party, until 1999 Liberal Party.

The proportion of votes cast and voting turnout are based on the elections data of Statistics Finland ${ }^{1}$. They are presented in Figure 1. The variables of government responsibilities contain information if the party has been in government or in opposition during the elections. The government data is based on the Finnish Minister Database MIKO published by the Finnish Government [4].

National economic conditions are analyzed using four measurements. The Change of Cost of Living Index (COLI) is used to measure inflation. The Unemployment Rate (UNEM) has significant influence on the daily life of the voters. The Change of Gross Domestic Product per Capita (CGDP) and the Change of Total Consumption per Capita (CCONSUM) are good measures for economic growth. These four monetary values are transformed into constant prices of the

${ }^{1}$ http : //www.stat.fi/index_en.html 


\begin{tabular}{|r|c|c|c|c|c|c|c|c|c|c|c|} 
Year & KESK & SDP & KOK & LEFT & GREEN & KD & RKP & PS & LIB & OTH. T.OUT \\
\hline 1954 & 24.1 & 26.2 & 12.8 & 21.6 & & & 6.8 & & 7.9 & 0.6 & 82.9 \\
1958 & 23.1 & 23.2 & 15.3 & 23.2 & & & 6.5 & & 5.9 & 2.8 & 78.3 \\
1962 & 23.0 & 19.5 & 15.0 & 22.0 & & & 6.1 & 2.2 & 6.3 & 5.9 & 86.1 \\
1966 & 21.2 & 27.2 & 13.8 & 21.1 & & 0.5 & 5.7 & 1.0 & 6.5 & 2.9 & 86.1 \\
1970 & 17.1 & 23.4 & 18.0 & 16.6 & & 1.1 & 5.3 & 10.5 & 6.0 & 2.0 & 83.2 \\
1972 & 16.4 & 25.8 & 17.6 & 17.0 & & 2.5 & 5.1 & 9.2 & 5.2 & 1.2 & 81.9 \\
1975 & 17.6 & 24.9 & 18.4 & 18.9 & & 3.3 & 4.7 & 3.6 & 4.3 & 4.3 & 80.1 \\
1979 & 17.3 & 23.9 & 21.7 & 17.9 & & 4.8 & 4.3 & 4.6 & 3.7 & 1.8 & 81.9 \\
1983 & 17.6 & 26.7 & 22.1 & 13.5 & & 3.0 & 4.9 & 9.7 & & 2.5 & 81.2 \\
1987 & 17.6 & 24.1 & 23.1 & 13.6 & 4.0 & 2.6 & 5.6 & 6.3 & 1.0 & 2.1 & 76.2 \\
1991 & 24.8 & 22.1 & 19.3 & 10.1 & 6.8 & 3.1 & 5.5 & 4.8 & 0.8 & 2.7 & 71.0 \\
1995 & 19.8 & 28.3 & 17.9 & 11.2 & 6.5 & 3.0 & 5.1 & 1.3 & 0.6 & 6.3 & 70.6 \\
1999 & 22.4 & 22.9 & 21.0 & 10.9 & 7.3 & 4.2 & 5.1 & 1.0 & 0.2 & 5.0 & 66.8 \\
2003 & 24.7 & 24.5 & 18.6 & 9.9 & 8.0 & 5.3 & 4.6 & 1.6 & 0.3 & 2.5 & 67.6 \\
\hline
\end{tabular}

Fig. 1. Proportion of votes cast for different parties and voting turnout in Parliamentary elections in 1954-2003 (\%) (Statistics Finland 2004, p. 11 and p. 15)

year 2000. For each measurement, there are three variables included in the data: the first at elections year (marked with $\operatorname{COLI}(\mathrm{T}), \operatorname{UNEM}(\mathrm{T}), \mathrm{CGDP}(\mathrm{T})$, and CCONSUM(T)), the second at a year before elections (marked with COLI(T-1), etc.) and the third at two years before elections (marked with COLI(T-2), etc.). The Change of Cost of Living Index, the Change of Gross Domestic Product per Capita and the Change of Total Consumption per Capita are based on the data provided by the Statistics Finland [17]. The Unemployment Rate is based on Keinänen's unemployment and employment statistics [8].

\subsection{Method and earlier work}

The Self-Organizing Map (SOM) $[9,10]$ has been used in a wide range of areas such as medicine, economics or in the analysis of industrial processes. In a paper closely related to this one, Kaski and Kohonen studied the socio-economic status of the countries in the world based on World Bank data [7]. Deboeck and Kohonen have edited a book that shows many examples of uses of the SOM in the area of finance [3]. Länsiluoto et al. conducted analysis of economic and competitive environment in the formulation of corporate strategies using the SOM [12]. Tuia et al. have used the SOM combined with Ward's classification to classify the municipalities of Western Switzerland, interpret the socio-economic landscape of the region [19]. Lendasse et al. [14] used the SOM in forecasting electricty consumption. In our work, we did not aim, for instance, to predict the results of next elections but rather provide a basis for interpreting the results and their relation to some socio-economic variables.

In the 2004 municipal and EU elections in Finland the candidates were mapped according to their answers to a number of questions. The voters could then use a web site of a major commercial broadcasting company that had an 
interactive version of the map. The users could answer the same questions that were presented to the candidates and then see where the like-minded candidates are positioned on the map.[1,2]

The SOM organizes data in such a way that the variables with largest variance affect the result most. In the case of relative approval ratings, no scaling is required as the figures are comparable as such. However, if the data consists of variables the status of which varies, scaling is needed. In the analysis described in Section 3, we have both relative approval ratings and some societal variables such as unemployment rate. In this study, data was normalized by dividing every variable with its variance. More detailed discussion on data normalization is provided e.g. in [10].

The study also shows how the value of different variables is distributed on the map. For interdisciplinary understandability we refer to these distributions as variable maps where the methodological community has often used the term component plane. In this study, we implemented the SOM using Matlab 7.0.1 with the SOM Toolbox 2.0.

\section{Results}

In the following, we present the results of the SOM-based analysis. We show the overall analysis of the relationship between the election years (Section 3.1) and discuss some specific findings (Section 3.2).

\subsection{Overall results}

Figure 2 presents the parliamentary election years organized by the SOM algorithm. It is possible to see that the parliamentary election years form roughly a kind of chain. Consecutive election years are typically close to each other on the map. This feature most likely reflects the idea that societal changes happen gradually.

On the right side of Figure 2, there is a distance map. The distance map reflects distances between the locations of the map, with a lighter shade of gray denoting a relatively longer distance. On Figure 3, there are the variable maps that shows how the value of different variables is distributed on the map. The elections of the years 1954, 1962 and 1966 form their own tight cluster. This cluster corresponds to the post war years when the combined popularity of the left wing parties and the Agrarian Union was high. The elections of the years 1958 and 1970 are slightly apart from this cluster. In the 1970 election, Finnish Rural Party (PS in the variable maps) climbed up to 10.5 per cent, being only at 1.0 per cent four years earlier. The party had been founded by a former member of Agrarian Union. The Agrarian Union, at that time the Centre Party (KESK) lost popularity: it dropped from 21.2 per cent to 17.1 per cent. This change is clearly seen on the map. In 1958 election, the inflation rate a year before the election was high (variable COLI(T-1)) as well as the popularity of the Democratic League of the People of Finland (LEFT). 

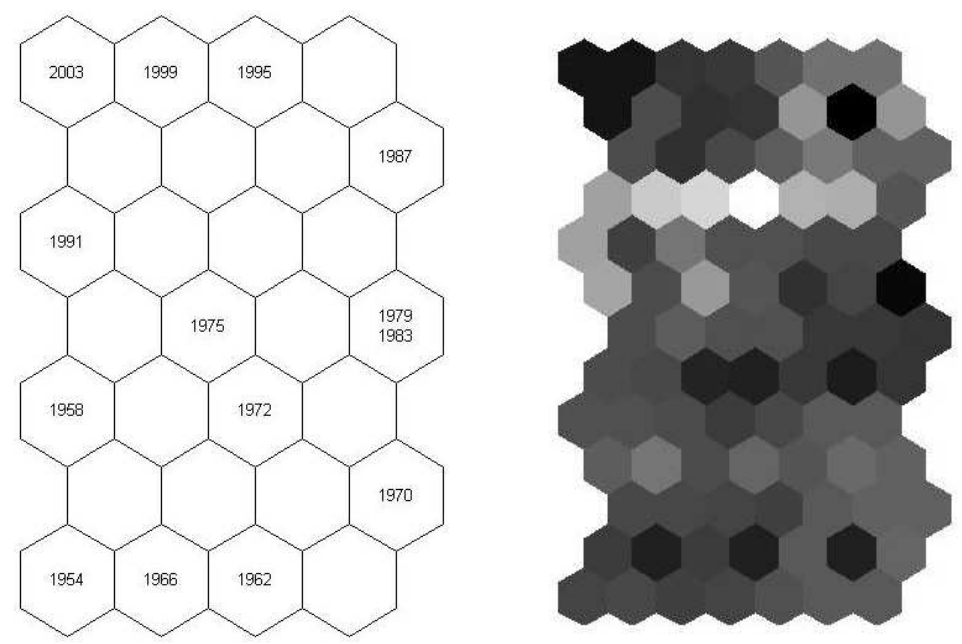

Fig. 2. Parliamentary election years organized by the SOM algorithm

The elections of the years 1972 and 1975 form a cluster of their own. The results of the 1972 elections were quite similar to those of the 1970 elections, except that the National Coalition Party (KOK) fell from the second place to the fourth in popularity. The variable maps show clearly that in that period the inflation rate was exceptionally high.

The elections of the years 1979 and 1983 form their own tight cluster. After a long period of being in the government, the Centre Party had lost much of its earlier popularity whereas the popularity of the National Coalition Party was increasing. The main issues in the 1979 parliamentary election were unemployment and taxation. In 1979, the unemployment rate was not as high as it is nowadays (see UNEM variable maps) but it had clearly grown from the earlier years.

The elections of the years 1987 and 1991 are distant from the main clusters. This period of time was particularly turbulent in Finnish 20th century history from the economical point of view. In October 1991, Finland and other EFTA member countries agreed to form a European Economic Area (EEA) with the EU from 1993 leading into Finland's EU membership in 1995. In the 1987 elections, the National Coalition Party (KOK) and conservative Prime Minister took office in 1987, heading a coalition government that included the Social Democrats. This left the Center party as the opposition for the first time since independence. The economic collapse of the USSR in 1991 caused a severe recession in Finland due to severely decreasing exports to Russia. Another factor causing the recession seems to be the liberalization of foreign loan policies. Korhonen describes this change as follows: "Perhaps the most significant change came with the granting of permission in 1986-1987 to raise long-term loans from abroad. The largest fundamental change occurred at the start of 1991, when the old comprehensive 

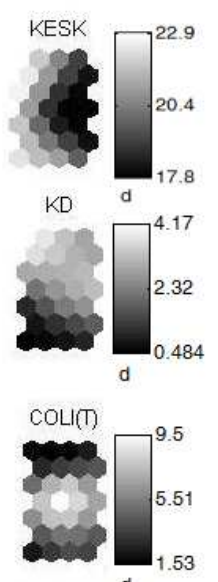

UNEM(T-2)

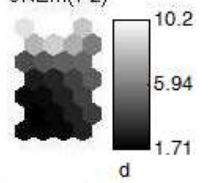

CONSUM(T-1)
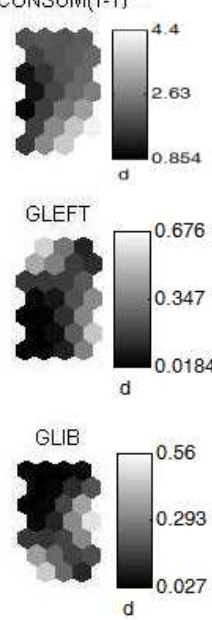

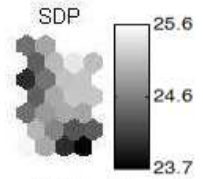

RKP d

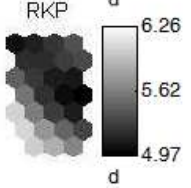

COLI(T-1)

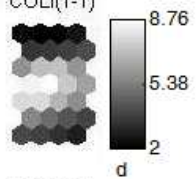

CGDP(

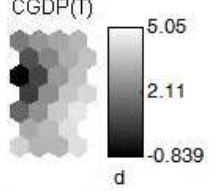

CCONSUM(T-2)
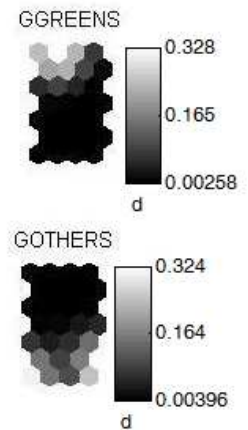

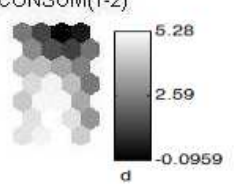

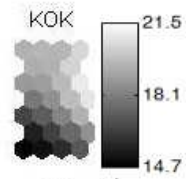
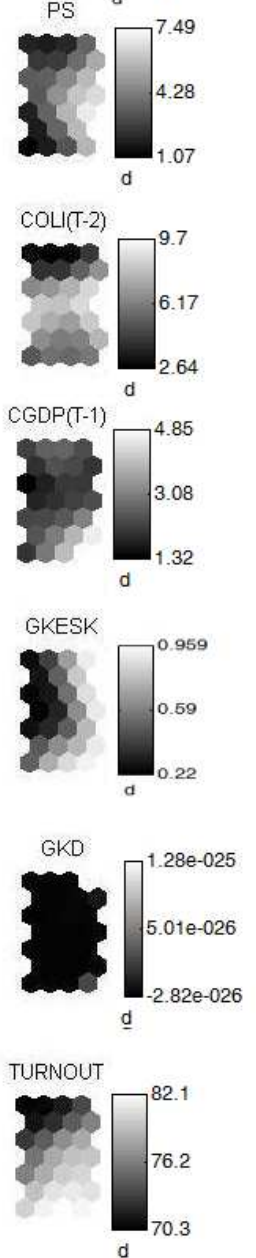
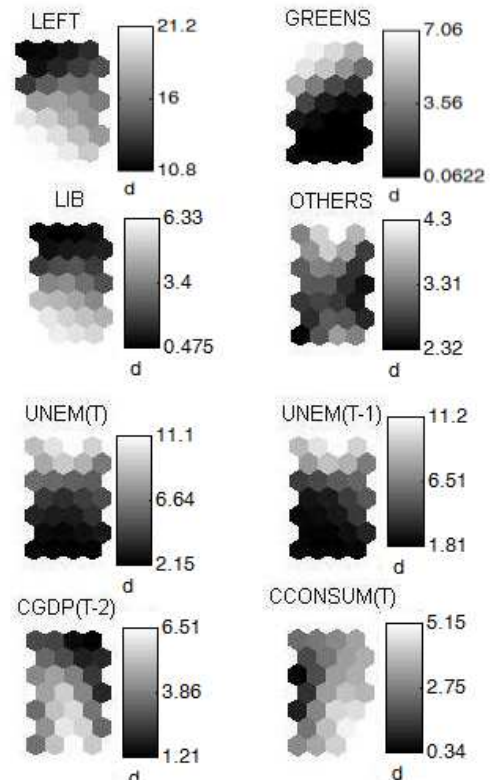

CCONSUM(T)
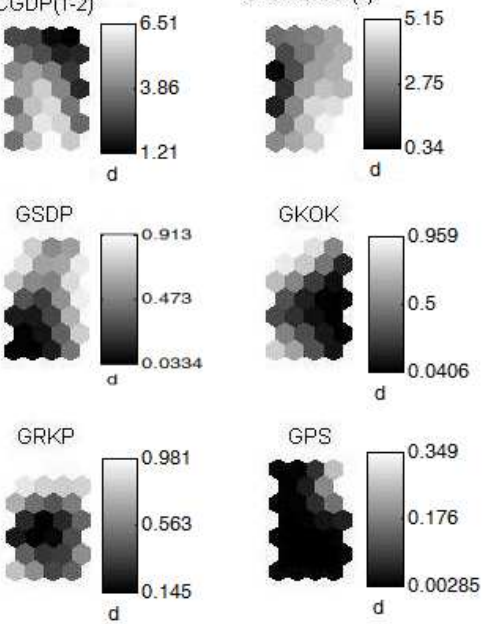

Fig. 3. The variable maps of all variables used in this study 
restriction was finally repealed; from then on, all foreign exchange dealings not specifically subject to approval by the Bank of Finland were unrestricted. Now foreign exchange restrictions remained only on the raising of loans abroad by private individuals and comparable corporate entities, and these were in turn lifted in October 1991 in accord with the spirit of the EEA Agreement."[11] This change lead into excessive foreign loan taking that appeared to contribute to the strong overall structural change including, among others, a strong increase of unemployment. However, when we consider the SOM analysis, these kind of conclusions cannot be drawn from the analysis results and diagrams alone. On the other hand, we have taken some time dynamics into account in the analysis by including "delayed variables": for instance, in addition to considering the unemployment rate at the year of election, we have also included the rate one and two years earlier.

The most recent elections of the years 1995, 1999 and 2003 form the cluster that is clearly apart from other elections. The most distinctive aspects include high level of unemployment, low popularity of the Left Alliance (LEFT), high popularity of the Greens (GREENS), and low level of turnout (TURNOUT). The low of turnout has raised questions about the passivity of the voters. However, at least two possible conclusions could be made. It could be, like often mentioned, that the politics has become more distant to the citizens due various reasons, one of which could be the EU membership and the relatively lower importance of national legislation. On the other hand, the economical recovery from the recession period of early 1990s may have increased the general feeling of satisfaction. This is not supported, though, by the variable maps that indicate the high degree of negative correlation between unemployment rate and turnout.

\section{$3.2 \quad$ Specific findings}

It is commonly believed that being in the government will cause a popularity reduction in the next election. Figure 4 shows that this is true for the four largest parties: Centre Party (KESK), Social Democratic Party (SDP), National Coalition Party (KOK) and Left Alliance (LEFT). This observation is not however valid for the other parties.

There is a strong negative correlation between the Centre Party (KESK) and inflation $(\operatorname{COLI}(\mathrm{T}), \operatorname{COLI}(\mathrm{T}-1)$ and $\operatorname{COLI}(\mathrm{T}-2))$. During high unemployment the popularity of the Centre Party has been decreasing and during low unemployment it has been increasing. The Centre Party's position as the largest party that has been many times in the government could cause these findings. Voters have punished it because of unfavorable economic situations or developments. This interpretation is in harmony with a study made by Lewis-Beck with French data[15]. The study shows that increasing unemployment and inflation result in popularity reduction for the French president and prime minister.

The popularity of the National Coalition Party (KOK) has the same feature as the popularity of the Centre Party. During high unemployment it has been decreasing and during low unemployment it has been increasing. During the existence of the Green League (GREENS) the approval ratings of the Social 


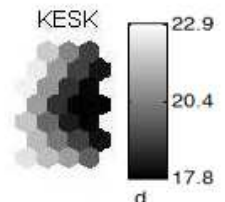

GKESK

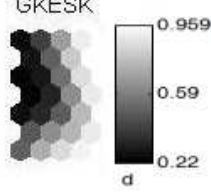

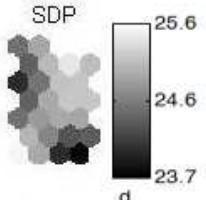

GSDP

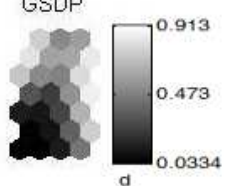

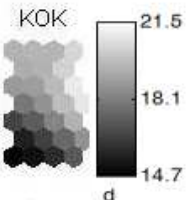

GKOK

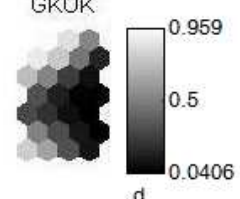

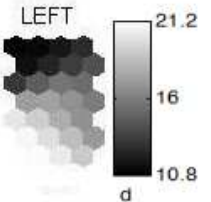

GLEFT

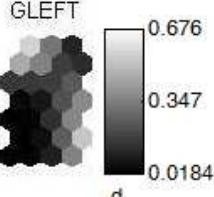

Fig. 4. Being in the government causes popularity reductions for the four largest parties in the next elections

Democratic Party and the Greens have had negative correlation. The popularity of the Left Alliance (LEFT) has been decreasing within the whole period of the study.

A change that took place in the late 1970s is clearly discernable. Many dependences between variables changed their features. Correlations turned from negative to positive and vice versa. For example, turnout has a positive correlation with the Change of Gross Domestic Product per Capita (CGDP(T), CGDP(T-1) and CGDP(T-2)) in the 1950s and 1960s. In the 1990s and 2000s, there is, on the contrary, a negative correlation. Earlier economic growth has potentially provided possibilities to be politically active and later it has made people negligent.

\section{Conclusions and discussion}

We have explored the relationship between parliamentary election results and political and societal situation in Finland. The data consisted of the parliamentary election results in Finland, the parties in the government by the time of and before each election, and a number of socioeconomic variables. We have used the self-organizing map algorithm as the data mining and visualization method. Using the method, we have been able to show how the parliamentary election results seem to reflect both the political and societal conditions with a large number of specific findings discussed above. We suggest that this approach can be used as a method that can serve as a bridge between qualitative and quantitative methods (see also [5]). The specific findings can serve as hypotheses that can be further studied with other statistical methods. In summary, the main ideas for the use of the data mining methodology includes the possibility of obtaining an overall picture, visual detection of correlations, and formation of hypothesis for further analysis. Future research possibilities include adding other potentially relevant variables and a more detailed analysis of time dependent phenomena. 


\section{References}

1. Berg, M., Kaipainen, M. \& Kojo, I. 2004. Enhancing Usability of the Similarity Map for More Accessible Politics. Proceedings in 8th ERCIM Workshop, User Interfaces For All, Vienna, Austria.

2. Berg, M., Marttila, T. Kaipainen, M. \& Kojo, I. 2006. Exploring Political Agendas with Advanced Visualizations and Interface Tools e-Service Journal, 4(2): 47-63.

3. Deboeck, G. \& Kohonen, T. (eds.) 1998. Visual Explorations in Finance with SelfOrganizing Maps. Berlin: Springer.

4. The Finnish Government n.d., MIKO-ministeritietojärjestelmä (The Finnish Minister Database). Retrieved November 13, 2005, from http://www.valtioneuvosto.fi/hakemisto/ministerikortisto/raportti.asp

5. Janasik, N., Honkela, T. \& Bruun, H. 2008. Text Mining in Qualitative Research: Application of an Unsupervised Learning Method. Organizational Research Methods. OnlineFirst. http://orm.sagepub.com/cgi/content/abstract/1094428108317202v1

6. Johansson, K.M. \& Raunio, T. 2001. Partisan responses to Europe: comparing Finnish and Swedish political parties. Eur. J. of Political Research, 39(2): 25-49.

7. Kaski, S. \& Kohonen, T. 1996. Exploratory data analysis by the self-organizing map: Structures of welfare and poverty in the world. Neural Networks in Financial Engineering, Singapore: World Scientific, pp. 498-507.

8. Keinänen, P. 1999, Työttömyys (Unemployment). Andreasson, K. \& Helin, V. (eds), Suomen vuosisata. Helsinki: Statistics Finland, pp. 74-79.

9. Kohonen, T. 1982. Self-organized formation of topologically correct feature maps. Biological Cybernetics, 43:59-69.

10. Kohonen, T. 2001. Self-Organizing Maps, 3rd Edition, Berlin: Springer.

11. Korhonen, T. 2001. Finnish monetary and foreign exchange policy and the changeover to the euro. Bank of Finland discussion papers.

12. Länsiluoto, A., Eklund, T., Back, B., Vanharanta, H. \& Visa, A. 2004. Industry Specific Cycles and Companies' Financial Performance - Comparison with SelfOrganizing Maps. Benchmarking - An International Journal, 11(4): 267-286.

13. Lee, J.A., Lendasse, A., Verleysen, M. 2004. Nonlinear projection with curvilinear distances: Isomap versus curvilinear distance analysis. Neurocomputing 57: 49-76.

14. Lendasse, A., Lee, J.A., Wertz, V. \& Verleysen, M. 2002. Forecasting electricity consumption using nonlinear projection and self-organizing maps. Neurocomputing 48(1-4): 299-311.

15. Lewis-Beck, M. S. 1980. Economic Conditions and Executive Popularity: The French Experience. American Journal of Political Science, 24: 306-333.

16. Martikainen, P., Martikainen, T. \& Wass, H. 2005. The effect of socioeconomic factors on voter turnout in Finland: A register-based study of 2.9 million voters. European Journal of Political Research, 44(5): 645-669.

17. Statistics Finland 2004, Parliamentary elections 2003, elections 2004:1, Edita Prima Oy, Helsinki, p. 8, p. 11 and p. 15.

18. Raunio, T. \& Tiilikainen, T. 2003. Finland in the European Union. London: Frank Cass.

19. Tuia, D., Kaiser, C., Cunha, A. and Kanevski, M. 2008. Socio-economic Data Analysis with Scan Statistics and Self-organizing Maps. Proceedings of the international conference on Computational Science and its Applications. Berlin: Springer, pp. $52-64$.

20. Venna, J. \& Kaski, S. 2006. Local multidimensional scaling. Neural Networks, 19(6): 889-899. 